\title{
Unternehmen
}

\section{Europäische Zentrale von Rotterdam nach Frankfurt verlegt}

Der US-Dentalhersteller Hu-Friedy hat seit Anfang August seine Europazentrale in Frankfurt. Als Drehscheibe für den Handel in Europa, Arabien und Afrika übernimmt der Standort eine Schlüsselrolle innerhalb des Konzerns. Ziel des Umzugs ist die optimale Versorgung der Märkte durch die größere Nähe zu Lieferanten und Produzenten. Die Verlagerung nach Deutschland wurde bereits letztes Jahr mit der Eröffnung eines neuen Logistikzentrums in Tuttlingen eingeleitet. Die Niederlassung in Rotterdam wird geschlossen. „Frankfurt befindet sich im Herzen des europäischen Dentalmarkts. Die einzigartige Lage und hervorragende Infrastruktur bieten ideale Voraussetzun- gen für die bestmögliche Betreuung unserer Kunden“ begründet Hu-Friedy Vorstand Ken Serota die Entscheidung. „Wir können Logistik und Auslieferung beschleunigen und profitieren bei der Produktentwicklung von der Nähe zu exzel-

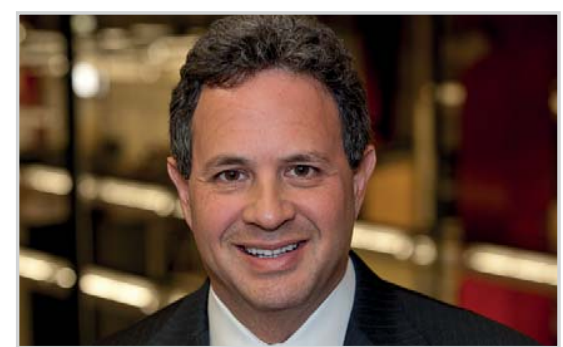

K. Serota lenten Universitäten und Wissenschaftlern. Darüber hinaus nutzen wir Synergieeffekte und können Doppelstrukturen beenden“" so der CEO.

In Frankfurt ansässig sind ab sofort die Abteilungen Marketing, Personal, Finanzen, Buchhaltung, IT sowie ein moderner Showroom. Vertrieb und Kundenservice für Nordeuropa sind ebenfalls in Frankfurt stationiert, während südeuropäische Klienten vom Büro in Mailand betreut werden. Im deutschen „Medical Valley“ Tuttlingen sind Logistik, Einkauf, Qualitätsmanagement, technischer Support und After-Sales-Service angesiedelt. In diesem Zentrum für Medizintechnik sind Lieferantennähe und permanenter Wissensaustausch und ebenso garantiert wie hoch qualifizierte Fachkräfte.

Nach einer Pressemitteilung der Hu-Friedy Mfg. Co., LLC., Frankfurt am Main www.hu-friedy.eu 